\title{
IMPLEMENTASI DIGITAL MARKETING PADA UMKM DI ERA REVOLUSI INDUSTRI 4.0 (STUDY PADA UMKM DI KABUPATEN SIDOARJO)
}

\author{
Nihlatul Qudus Sukma Nirwana ${ }^{1}$, Sarwendah Biduri ${ }^{2}$ \\ Universitas Muhammadiyah Sidoarjo
}

\begin{abstract}
This study aims to determine how the implementation of digital marketing in MSMEs in the era of the Industrial Revolution 4.0. The analysis in this study used descriptive quantitative method with questionnaire as the data collection technique. The population in this study were MSMEs in Sidoarjo Regency with a sample size of 32 MSMEs. Data analysis was carried out in four phases, namely editing, coding, tabulation, and data analysis. The results of the study explained that the implementation of digital marketing in the development of industry 4.0 at MSMEs in Sidoarjo Regency had not yet been implemented due to lack of training, business capital, human resources, unfulfilled development strategies, traditional business characteristics and high consulting costs.
\end{abstract}

Keywords $\quad$ : Digital Marketing; MSMEs; Industrial Revolution 4.0

Correspondence to : nihlaqsn@umsida.ac.id

\begin{abstract}
ABSTRAK
Penelitian ini bertujuan untuk mengetahui bagaimana implementasi digital marketing pada UMKM di era Revolusi Industri 4.0. Analisis dalam penelitian ini menggunakan metode deskriptif kuantitatif dengan teknik pengumpulan datanya menggunakan angket. Populasi dalam penelitian ini adalah UMKM di Kabupaten Sidoarjo dengan jumlah sampel 32 UMKM. Analisis data dilakukan dalam empat tahap, yaitu penyuntingan, pengkodean, tabulasi, dan analisis data. Hasil penelitian menjelaskan bahwa implementasi digital marketing dalam pengembangan industri 4.0 pada UMKM di Kabupaten Sidoarjo belum terlaksana karena kurangnya pelatihan, modal usaha, sumber daya manusia, strategi pengembangan yang belum terpenuhi, karakteristik bisnis tradisional dan konsultasi yang tinggi biaya.
\end{abstract}

Kata Kunci : Digital Marketing; UMKM; Revolusi Industri 4.0

\section{Riwayat Artikel:}

Received : 25 November 2020

Revised: 03 Desember 2020

Accepted : 15 Januari 2021 


\section{PENDAHULUAN}

Sejak tahun 2011 isu tentang perkembangan revolusi industri 4.0 sudah mulai di implementasikan oleh para pelaku industri berskala besar maupun kecil, namun hal itu merupakan anggapan belaka yang menjadi dilema kalangan pelaku usaha akan tetapi sejak tahun 2020 dengan adanya fenomena wabah Covid-19 dapat menyebabkan kelumpuhan pada perekonomian negara oleh karena itu para pelaku usaha harus tetap survive agar tidak termakan oleh arus. Hal ini menjadikan pelaku usaha dalam sekala besar maupun kecil bersaing untuk mengembangkan inovasi baru agar dapat mencapai tujuan yang telah diinginkan. Inovasi yang dilakukkan oleh pelaku usaha dapat mewujudkan perkembangan revolusi industri 4.0. Implemetasi Industri 4.0 berdampak pada perubahan usaha yang berawal dari usaha sederhana menjadi usaha yang modern untuk menyesuaikan perkembangan teknologi informasi dan big data.

Revolusi industri 4.0 merupakan suatu perubahan yang dapat diwujudkan dengan proses menghasilkan suatu produk (Arsad, 2018). Oleh karena itu perubahan usaha pada masa sekarang ini telah mengalami perkembangan yang pesat seiring dengan kemajuan teknologi yang ada, hal ini menyebabkan terjadinya perubahan otomatisasi hampir di semua bidang.

Salah satu contoh perkembangan pertumbuhan di Indonesia yang berkontribusi andil untuk memajukan negara yaitu Usaha Mikro Kecil dan Menengah (UMKM). Usaha ini mempunyai peran yang sangat strategis dalam pembangunan ekonomi nasional. Oleh karena itu selain berperan dalam pertumbuhan ekonomi dan penyerapan tenaga kerja juga berperan dalam pendistribusian hasil-hasil pembangunan. Dalam krisis ekonomi yang terjadi di negara kita sejak beberapa tahun yang lalu, banyak usaha berskala besar yang mampu bersaing untuk meningkatkan strategi usaha agar perusahaan tetap sukses. Hal ini ditunjukkan dengan adanya aktifitas sektor Usaha Mikro Kecil dan Menengah (UMKM) yang terbukti lebih tangguh dalam menghadapi krisis ekonomi

2017).

Performance UMKM dapat dilihat dari karakteristik wirausaha, modal usaha, dan strategi pengembangan UMKM. Menurut Purwanti, (2012), wirausaha umumnya mempunyai sifat dan karakteristik yang sama yaitu mempunyai keinginan yang tinggi (niat), keinginan berinovasi, kemampuan menerima tanggung jawab secara individu agar dapat meningkatkan prestasi kerja agar mencapai tujuan yang diinginkan serta kemampuan manajemen yang bagus.

Berdasarkan data yang dikemukakan oleh Bank Indonesia (2015) menunjukkan permasalahan UMKM dari sisi kuantitas belum dapat melibatkan lebih banyak tenaga kerja karena keterbatasan kemampuan menggaji. Keterbatasan ini menyebabkan produktivitas UMKM buruk yaitu rendahnya kemampuan untuk mengelola manajemen usaha baik dalam bidang manajerial, teknologi digital dalam mengembang pemasaran, strategi pengembangan dan modal yang disebabkan kurangnya pengetahuan tentang dunia bisnis.

Hasil penelitian yang di lakukkan bank Indonesia (2015) sejalan dengan penelitian yang dilakukkan oleh Oktaviani \& Rustandi, (2018) dalam penelitiannya menjelaskan bahwa kendala yang dihadapi oleh pelaku UMKM yang dipengaruhi oleh faktor internal dan eksternal, hambatan baik internal maupun eksternal salah satunya adalah perkembangan teknologi melalui digital yang sulit untuk di implementasikan karena kurangnya sumber daya manusia. Sedangkan dalam penelitian yang dilakukkan oleh Sanjaya, et.al (2020) berbeda pendapat dimana digital marketing dalam menjalan usaha mampu menerapkan teknologi informasi berbasis digitalisasi yang dibuktikan dengan signifikanya penjualan produk pada BUMDes Berdikari sehingga penjualan produk meningkat dan semakin berkembang serta mampu menggeliatkan perekonomian desa menuju masyarakat yang makmur.

Akbar, Apip, \& Usmar, (2018) dalam mengahadapi era digital seperti sekarang ini, UMKM di Indonesia harus memiliki strategi untuk meningkatkan daya saing, agar tidak 
tertinggal oleh perkembangan teknologi yang semakin pesat. Tentunya banyak celah yang dapat dimanfaatkan fasilitas atau programprogram dari pemerintah dan stakeholders lainnya. Kominfo, (2018) menjelaskan bahwa perubahan revolusi industri 4.0 merupakan era baru bagi para entrepreneur di Indonesia yang harus dijadikan sebagai peluang emas untuk meningkatkan kinerja usahanya.

Sandy, (2017) menyatakan bahwa lompatan besar terjadi di dunia wirausaha khususnya sektor industri, dimana teknologi informasi dan komunikasi dimanfaatkan sepenuhnya. Terlebih kota Sidoarjo, kabupaten yang menjadi salah satu penyangga ibu kota provinsi Jawa Timur ini dijuluki kota Udang, rupanya Sidoarjo tidak hanya memiliki potensi sumber daya alam yang luar biasa akan tetapi penggunaan sistem informasi untuk dapat meningkatkan pemasaran dan volume penjualan suatu produk belum maksiamal. Kabupaten Sidoarjo prospektif untuk dijadikan daerah investasi karena jumlah Usaha Mikro Kecil Menengah (UMKM) disana mencapai 171.264 unit usaha. Rinciannya, usaha mikro 154,891 unit, usaha kecil menengah 154 unit, dan usaha besar 16.000 unit. Di Sidoarjo juga telah tumbuh sekitar 82 sentra industri rakyat dan 11 kampung usaha, seperti kampong batik. Kampong jajanan, kampong kerupuk, kampong sayangan, kampong sandal dan sepatu, dll. Hal ini perlu adanya campuran pengembangan industri 4.0 agar usaha Mikro Kecil Menengah (UMKM) di Sidoarjo mampu bersaing dengan daerah yang lain.

Berdasarkan fenomena dan research Gap yang terjadi di atas maka dalam penelitian ini bertujuan untuk mengetahui bagaimana implementasi digital marketing pada UMKM di era revolusi industri 4.0 (Study Pada UMKM di Kabupaten Sidoarjo)

\section{METODE PENELITIAN}

Penelitian ini menggunakan jenis penelitian deskriptive quantitative. Lokasi penelitian di UMKM daerah Sidoarjo. Peneliti memilih lokasi atau tempat penelitian yaitu pada UMKM Makanan dan Minuman yang berada di Kabupaten Sidoarjo. Populasi dalam penelitian ini adalah UMKM Makanan dan
Minuman di Kabupaten Sidoarjo yang telah terdaftar di Dinas Koperasi dan Mikro Kabupaten Sidoarjo yang berjumlah 168 UMKM. Berdasarkan perhitungan Slovin dari populasi 168 UMKM dapat ditarik kesimpulan hanya 32 sampel yang dapat digunakan. Penarikan sampel pada penelitian ini menggunakan metode nonprobability sampling dengan metode purposive sampling dimana sampel di nilai sebagai sampel yang memiliki kriteria Sugiyono, (2016) yaitu UMKM Makanan dan Minuman yang terletak di Kabupaten Sidoarjo, UMKM yang sudah berdiri minimal 3 tahun, UMKM yang memiliki tenaga kerja minimal 3 karyawan. Teknik pengumpulan data menggunakan kuisioner menggunakan media google form. Adapun teknik analisis data yang digunakan dalam penelitian ini menggunakan empat metode yang terdiri dari editing, coding, tabulasi dan analisis data.

\section{HASIL PENELITIAN}

Hasil survey pada penelitian ini ditunjukkan berdasarkan identifikasi sampel yang digunakan dalam penelitian ini yang ditunjukkan sebagai berikut:

Hasil survey responden berdasarkan lama berdiri UMKM

\section{Gambar 1: Diagram Hasil Survey Responden Berdasarkan Lama Usaha Berdiri}

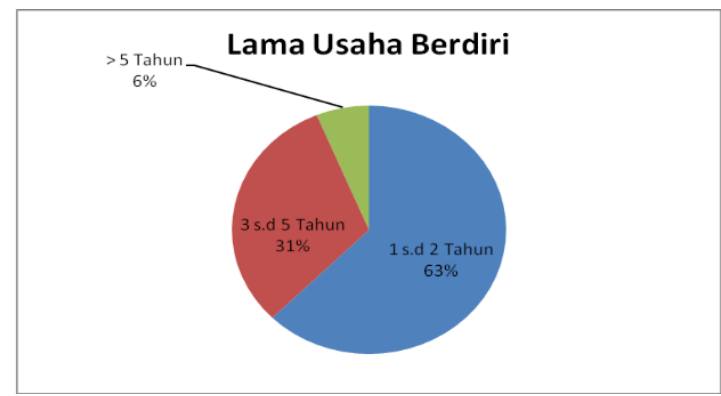

Sumber: Data diolah Peneliti 2020

Hasil survey pada gambar 1 diatas dapat dijelaskan bahwa UMKM makanan dan minuman di kabupaten Sidoarjo yang digunakan dalam penelitian ini berdasarkan 
lama berdiri 1-2 tahun sebesar $63 \%$ dan Sisanya berdiri 3-5 tahun sebanyak $31 \%$.

Hasil survey responden berdasarkan jumlah karyawan

Gambar 2: Diagram Hasil Survey Responden Berdasarkan Jumlah Karyawan

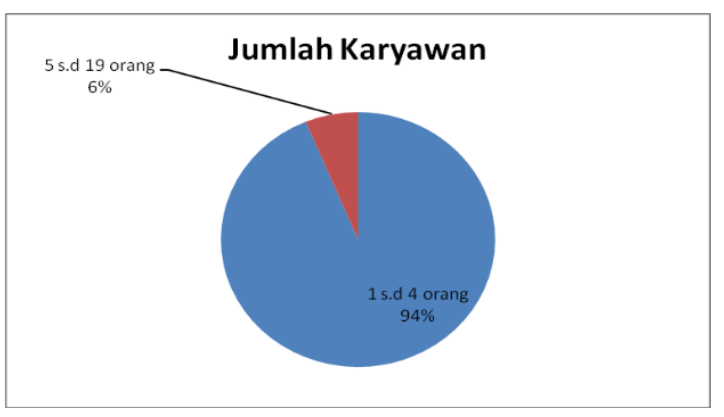

Sumber: Data diolah Peneliti 2020

Hasil survey pada gambar 2 diatas dapat dijelaskan bahwa UMKM makanan dan minuman di kabupaten Sidoarjo yang digunakan dalam penelitian ini berdasarkan jumlah karyawan 1 sampai dengan 4 orang sebanyak $94 \%$ dan sisanya 5-19 orang hanya $6 \%$.

Besarnya Implementasi Penggunaan Digital Marketing Oleh Para UMKM.

Berdasarkan hasil survey para pelaku UMKM masih belum semua mengimplementasikan penggunaan digital marketing dalam proses transaksi jual belinya hal ini ini dapat di paparkan pada gambar 3 sebagai berikut:

\section{Gambar 3: Hasil Survey Penggunaan Digital Marketing}

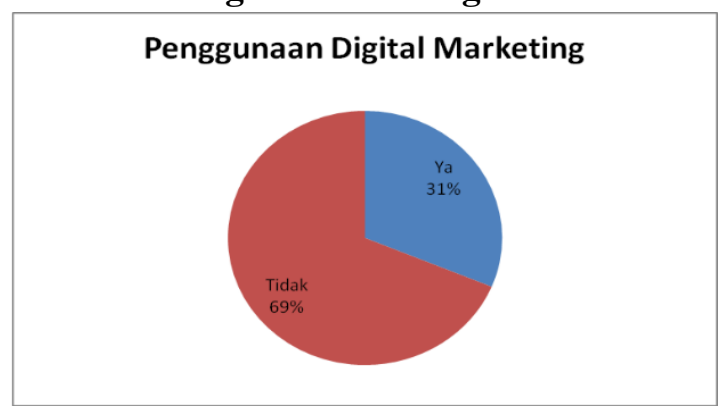

Sumber: Data diolah Peneliti 2020

Hasil survey pada grafik 3 diatas dapat dijelaskan bahwa 32\% UMKM di Kota Sidoarjo menggunakan Digital Marketing dalam proses jual beli dan sisanya 69\% menggunakan cara tradisional dalam proses jual belinya. Hal ini di sebabkan oleh beberapa alasan mengapa para UMKM belum mampu untuk mengimplementasikan digital Marketing yaitu dapat dipaparkan dalam gambar 4 di bawah ini:

Gambar 4: Hasil Survey Masalah Implementasi Digital Marketing

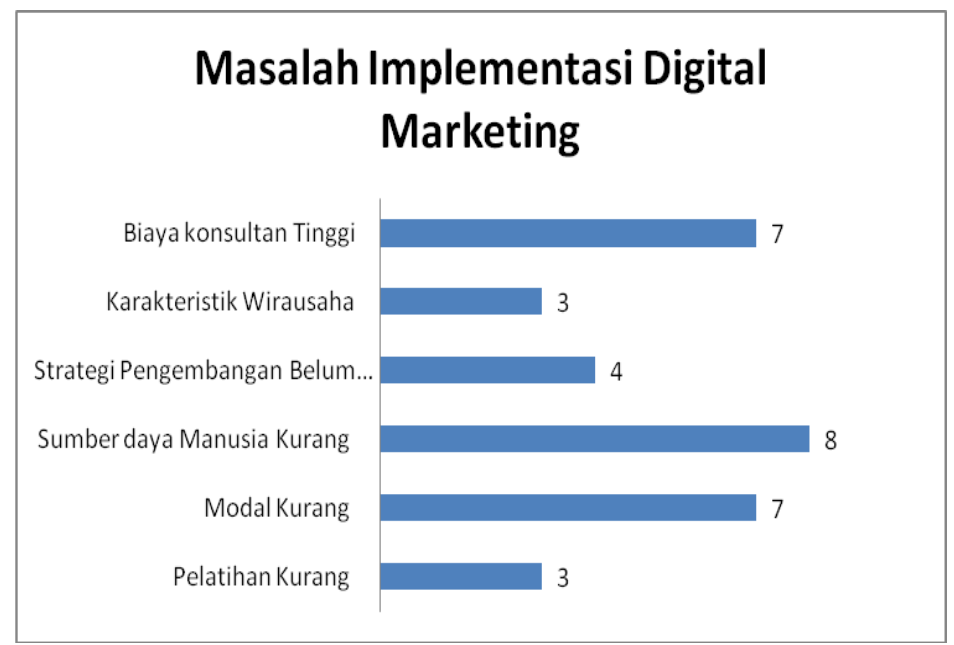

Sumber: Data diolah Peneliti 2020 
Hasil survey pada grafik 4 diatas dapat dijelaskan bahwa jawaban para pelaku usaha dapat ditunjukkan bahwa ada 6 masalah yang dihadapi 1) besarnya biaya konsultasi agar pelaku UMKM dapat mampu mengembangkan usaha pada industri 4.0,2) karakteritik wirausaha yang belum sepenuhnya di miliki oleh pelaku UMKM hal ini menyebabkan para pelaku UMKM belum dapat menemukan jati diri sehingga belum dapat fokus dalam pengembangan industri 4.0, 3) Strategi pengembangan belum terimplementasikan dimana hanya sebuah rencana saja dalam perancanangan strategi hal ini disebabkan karena 4) sumber daya manusia yang kurang serta 5) modal yang kurang terutama bagi para pelaku UMKM dan 6) pelatihan yang belum maksimal yang disebabkan karena pendampingan yang kurang merata. Berdasarkan hasil survey dapat ditunjukkan implementasi digital marketing yang digunakan oleh UMKM dapat dijelaskan sebagai berikut:

Gambar 5. Hasil Survey Penggunaan Digital Marketing

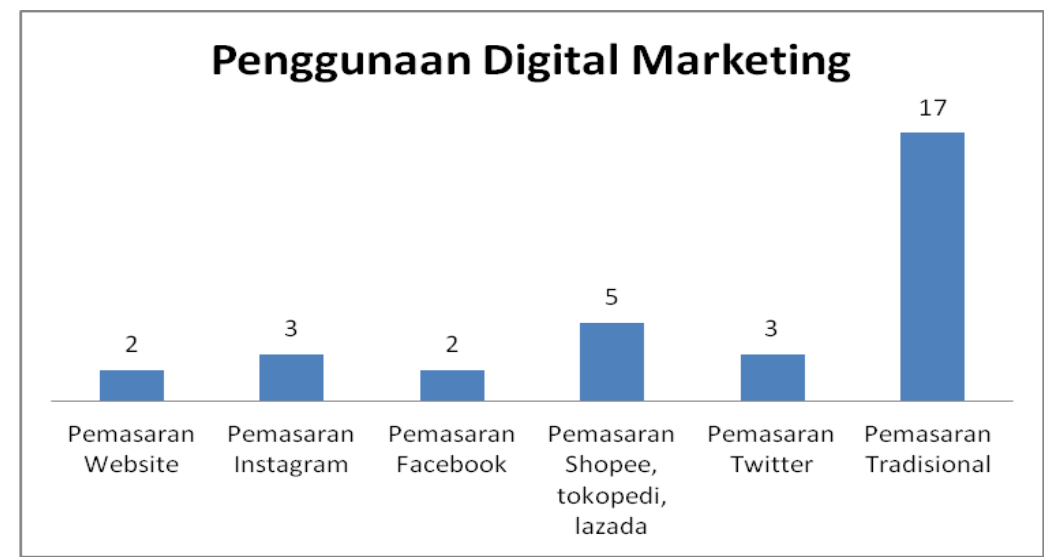

Sumber: Data diolah Peneliti 2020

Hasil survey pada grafik 5 diatas dapat dijelaskan bahwa penggunaan digital marketing dapat terlihat dengan jelas bahwa pemasaran Tradisional masih dominan hal ini dibandingkan dengan menggunakan digital marketing lainnya hal ini mengakibatkan industri UMKM semakin terpuruk.

\section{PEMBAHASAN}

Dari hasil analisis diketahui bahwa para UMKM dalam menggunakan digital marketing lebih sedikit dibandingkan dengan pemasaran tradisional. Pelaku UMKM belum mampu untuk mengimplementasikan digital Marketing dikarenakan sumber daya pelaku usaha kurang siap dalam berinovasi serta minimnya pengetahuan tentang penggunaan pemasaran secara digital. Tidak semua pelaku UMKM dapat menggunakan fasilitas dalam tekhnologi untuk melakukan konsultasi dalam pengembangan bisnisnya memerlukan biaya yang tinggi sehingga mereka hanya dapat melakukan pemasaran secara tradisional dan memerlukan modal yang cukup bersar. Hasil penelitian diatas merujuk dari hasil penelitian internal yang dilakukan oleh (Sukma, N.Q. et al, 2016) dalam penelitiannya bahwa Para pelaku UMKM di kabupaten Sidoarjo masih belum siap dalam mengahadapi perkembangan industri di Era Revolusi Industri 4.0 hal ini disebabkan karena 1) karakteristik pelaku usaha yang masih terhitung tradisional hal ini disebabkan karena banyak pelaku usaha yang masih belum memiliki latar belakang berwirausaha sehingga untuk menciptakan ide kreatif dan inovatif yang berakibat berkembangnya produk-produk dipasaran dan selalu mempunyai keinginan untuk dapat bersaing dengan keunggulan yang dimiliki, mampu mengelola tenaga kerja sehingga akan mempunyai tenaga kerja yang loyal dan 
mempunyai produktifitas yang tinggi dan berani bertanggung jawab dengan barang yang dihasilkan yang berarti wirausaha berani menanggung kualitas barang yang dihasilkan berani menerima masukan dan tantangan atas barang yang dihasilkan masih belum terlaksana. 2) Pelaku UMKM di kabupaten Sidoarjo masih kesulitan dalam mendapatkan permodalan dan pelatihan dikarenakan pembagian belum dilakukan secara merata hal ini di sebabkan karena syarat pengajuan modal usaha sangat sulit sehingga untuk UMKM masih belum mampu untuk mengimplementasikan dan juga karena keterbatasan yang di miliki serta pelaksanaan starategi pengembangan belum terlaksana hal ini disebabkan banyak sekali UMKM yang masih memiliki sumber daya manusia sedikit di era industi 4.0 ini. Peran sumber daya manusia sangat dibutuhkan untuk pengelolahan pengembangan ukm salah satunya adalah pengelolahan teknologi, sehingga pola berfikir masih terbatas

\section{KESIMPULAN}

Berdasarkan hasil penelitian dan pembahasan dapat disimpulkan bahwa implementasi digital marketing dalam pengembangan industri 4.0 pada UMKM di Kabupaten Sidoarjo masih belum terlaksana hal ini disebabkan karena kurangnya pelatihan, modal usaha, sumber daya manusia, strategi pengembangan yang belum terpenuhi, karakteristik usaha yang trasidional serta biaya konsultasi yang tinggi. Berdasarkan hasil penelitian disarankan untuk penelitian selanjutnya berfokus pada pelatihan dan pendampingan secara merata, kepada para UMKM di Sidoarjo.

\section{DAFTAR PUSTAKA}

Akbar, D. S., Apip, M., \& Usmar, D. (2018). STRATEGI Pengembangan Umkm Dalam Menghadapi Era Industri 4.0: Dalam Perspektif Akuntansi. ISEI Accounting Review, 2(1), 43-48. https://doi.org/https://doi.org/10.3621 7/iar.v2i2.72
Arsad, M. (2018, December). Revolusi Industri 4.0 Antara Peluang \& Ancaman Bagi Umkm. Arsadcorner.Com. Retrieved from http://www.arsadcorner.com/2018/12 /revolusi-industri-40-antarapeluang.html

Hertanto, A. (2017). Empat Strategi Indonesia Masuk Revolusi Industri Keempat. Kementrian Preinsdustrian Republik Indoanesia. Retrieved from https://kemenperin.go.id/artikel/1756 5/Empat-Strategi-Indonesia-MasukRevolusi-Industri-Keempat

Kominfo. (2018). Berhasil Kembangkan UMKM Pemkab Sidoarjo Raih Penghargaan Natamukti dari Menteri Koperasi dan UKM. Retrieved November 16, 2018, from Kabupaten Sidoarjo website: http://portal.sidoarjokab.go.id/berhasi 1-kembangkan-umkm-pemkabsidoarjo-raih-penghargaannatamukti-dari-menteri-koperasi-danukm

Oktaviani, F., \& Rustandi, D. (2018). Implementasi Digital Marketing dalam Membangun Brand Awareness. PRofesi Humas: Jurnal Ilmiah Ilmu Hubungan Masyarakat, 3(1), 1. https://doi.org/10.24198/prh.v3i1.158 78

Purwanti, E. (2012). Pengaruh Karakteristik Wirausaha, Modal Usaha, Strategi Pemasaran Terhadap Perkembangan Umkm Di Desa Dayaan Dan Kalilondo Salatiga. Jurnal Among Makarti, 5(1), 13-28. https://doi.org/10.1007/BF02532975

Sandy, A. K. (2017). Sidoarjo Kota UKM. Retrieved Februar1 5, 2017, http://ayukartikasandy.wordpress.co m/2017/02/12/sidoarjo-kota-ukmindonesia/

Sanjaya, P. K. A., Hartati, N. P. S., \& Premayani, N. W. W. (2020). Pemberdayaan Pengelola Badan 
BALANCE: Economic, Business, Management, and Accounting Journal Vol. XVII No. 1 |Bulan Januari tahun 2021 P-ISSN 1693-9352 | E-ISSN 2614-820x

Usaha Milik Desa ( BUMDes ) Berdikari Melalui Implementasi Digital Marketing System. Carrade : Jurnal Pengabdian Kepada Masyarakat, 3(1), 65-75.
Sugiyono. (2016). Metode Penelitian Kuantitatif, Kuaalitatif, dan R\&D. Alfabeta. 